\title{
Profissão Docente: profissionais complexos exige formação complexa
}

\section{Teaching Profession: complex professionals require complex training}

\author{
Dejane Figueiredo Barros ${ }^{1 *}$, Kenia Ariádna Santos Marinho ${ }^{1}$, José Carlos de Melo ${ }^{1}$
}

\begin{abstract}
RESUMO
Este estudo tem como intuito apontar, evidenciar a formação e profissão docente dentro de suas nuances e complexidades. Galgando o caminho de um estudo vasto de literatura, como: André (2016); Gauthier (2003); Imbernón (2011); Papi (2005); Tardif (2014), dentre outros, tal pesquisa identifica-se como de natureza aplicada, pois, vemos a possibilidade de produção de novos conhecimentos, uma abordagem quanti-qualitativa, já que mensura e avalia os dados coletados no questionário com perguntas abertas, e tem como objetivo examinar, explorar tal conhecimento da forma que é apresentado, aponta como procedimento um vasto estudo bibliográfico e ademais de um questionário para coleta de dados de 31 (trinta e um) participantes do IEMA UP Rio Anil. Desse modo, a averiguação das falas escritas obtidas nas arguições evidencia uma importância dada à necessidade da preocupação com a formação, profissão e valorização docente, pois, tornou-se evidente que a formação inicial e continuada das/dos docentes é o caminho para o bom desempenho do fazer pedagógico e assim, contribuir de modo significativo dentro deste ofício, que é ser professora e ser professor.
\end{abstract}

Palavras-chave: Docente. Profissão. Formação.

\section{ABSTRACT}

This study intends to point out, highlight the training and teaching profession within its nuances and complexity. Moving up the path of a vast study of literature, such as: André (2016), Gauthier (2003), Imbernón (2011), Papi (2005), Tardif (2014), among others, such research identifies itself as being of an applied nature, because we see the possibility of production of new knowledge, a quanti-qualitative approach, as it measures and evaluates the collected data in the questionnaire with open questions, and aims to examine, explore such knowledge in the way it is presented, it points out as a procedure a vast bibliographical study and also a questionnaire for data collection from 31 participants of the IEMA UP Rio Anil. The investigation of the written statements obtained in the arguments shows the importance given to the need to be concerned with the formation, profession and valuation of teachers, as it became evident that the initial and continuing teachers training is the way to a good performance in teaching and thus contribute significantly within this profession, which is to be a teacher and to be a teacher.

Keywords: Teacher. Profession. Formation.

\footnotetext{
${ }^{1}$ Universidade Federal do Maranhão - UFMA/PPGEEB.

*E-mail: dejane.fb@gmail.com
} 


\section{INTRODUÇÃO}

A discussão sobre a profissão docente se faz presente desde os tempos remotos até os dias atuais, na relação entre, quem ensina e para quem ensina, pois, assim como a sociedade em que é desempenhada está em constante evolução, com o trabalho docente não é diferente, o fazer pedagógico é um ofício em constante evolução, isto é, evolui de acordo com a época e as exigências da sociedade na qual está inserido o ato de transmitir, ensinar e trocar conhecimentos. Logo, nesse contexto, é preciso entender o desenvolvimento das categorias formação - profissão - identidade e saberes da profissãodocente.

Desse modo, o presente artigo é resultado de um estudo desenvolvido como prérequisito de conclusão da Disciplina "Formação, Saberes e Identidade Profissional da Docência" do Programa de Gestão do Ensino da Educação Básica (PPGEEB/ UFMA). O artigo propõe relacionar os conteúdos aprendidos na disciplina com os aspectos práticos da formação do professor, para isso vai tentar responder o seguinte questionamento: Como a formação contribui para a prática de profissionais tão complexos como os da profissão docente?

Por sua vez, foi empreendida a revisão de literatura estudada na disciplina expondo ideias-chave acerca dos saberes da docência e a profissão do professor e da sua formação comprometida com a construção de saberes e identidade docente, ademais de como se relacionam com a formação-profissão-ensino. Logo, é um estudo de caráter exploratório, assim, inicialmente dialogou-se sobre as categorias, formação e profissão docente com os autores Gauthier e Imbernón e as autoras Pappi e Veiga, dentre outros, contextualizando seu significado dentro da sociedade e reconhecendo a complexidade que tem o ofício da docência no campo da educação por lidar com seres complexos, em uma sociedade em constante transformação.

Em seguida, destacou-se alguns aspectos de como vem sendo realizada a prática da formação inicial e continuada do docente, apontando alguns caminhos, dialogando também com Tardif e Pimenta. Num outro momento, destacou-se as falas das docentes e dos docentes participantes da pesquisa, tentando analisá-las e discutí-las no contexto das categorias abordadas e nos apoiando nos teóricos já referidos, por sua vez, encerrando o estudo com as considerações finais. 


\section{A FORMAÇÃO E A PROFISSÃO DOCENTE: Evidenciando suas nuances}

A prática e a profissão docente podem-se dizer, com o intuito de delimitar o tempo e espaço, desde a Antiga Grécia, a qual tinha como principais polis/cidades Atenas e Esparta, em que cada uma tinha uma intenção distinta na formação de seus povos. A primeira buscava formar para o intelecto, raciocínio, inteligência e a segunda para as armas, lutas e guerras. E, desse modo, a educação vai se construindo de acordo com seus objetivos e intenções.

Dentro desse enredo, os responsáveis em transmitir determinados conhecimentos, em determinada época e consoante à demanda do momento que a sociedade exige esses profissionais, denominados de professoras e professores vão evidenciando as características e nuances de sua profissão. E, dessa forma, adquirindo conhecimentos, atitudes e habilidades em sua atuação docente.

Porém, é importante salientar o que Gauthier (2013) afirma,

É claro que basear o ensino no conhecimento do conteúdo, no "bomsenso", na experiência, na intuição, no talento ou numa vasta cultura não favorece de modo algum a formalização de saberes e de habilidades específicos ao exercício do magistério (GAUTHIER, 2013, p. 28).

Logo, os saberes e as características da profissão docente vão se delimitando e alicerçando a partir dos conhecimentos provenientes da própria profissão docente e dos desafios que vão se colocando na realidade, demandando um tipo de formação. Assim, ocorre que, na prática, esta se torna distanciada do ato de ser professora ou professor, e, como afirma Gauthier (2013), a grande chave do problema é identificarmos o "repertório de conhecimentos" no fazer pedagógico.

Compreender as nuances da profissão docente exige conhecer pormenores, como: ofício, ensino, aprendizagem, identidade profissional, relação professor-aluno, saber profissional docente, competências e habilidades inerentes ao ato de ensinar. A compreensão dessas nuanças está atrelada à formação inicial e contínua, já que como qualquer outro profissional, a melhoria das práticas do professor de carreira depende em grande parte da busca por saberes que o habilite e ajude a cumprir seu principal objetivo, que é ser mediador, mediadora de determinado conhecimento aos educandos e educandas sob sua responsabilidade. 
A formação docente objetiva contribuir para o desenvolvimento e o bom desempenho da profissão de ser professor, possibilitando o autoconhecimento, além de nos identificar e nos construir como profissionais da educação. Acerca desse pensamento Veiga (2015) nos lembra que, "a palavra profissão é uma construção social, é uma realidade dinâmica e contingente, calcada em ações coletivas. É produzida por ações de atores sociais - no caso os docentes".

No que concerne à profissionalização da profissão, como bem afirma Pappi (2013), "as profissões diferenciam-se pelos conhecimentos que lhes são específicos e pela configuração de uma prática consoante com as determinações de um ofício". Assim, nos leva a aprofundar termos como, por exemplo, ofício, que Pappi (2005) explica com muita propriedade, quando fala que o ofício de qualquer profissão se desenvolve decorrente do local em que é desempenhado.

Assim sendo, não iria ser diferente na profissão docente, que adquire suas características, que é "um ofício feito de saberes", como afirma Gauthier (2013). E, retomando o pensamento de Silmara Pappi, quando diz que o ofício, é o que é, devido ao local em que desenvolve o seu labor, que nesse caso é a sala de aula, e, assim vai o profissional da profissão-professor atribuindo-lhe singularidades provenientes do local em que executa sua atividade profissional.

Corroborando, Gauthier (2013) assegura que,

[...] não podemos identificar, no vazio, os saberes próprios ao ensino; devemos levar em conta o contexto complexo e real no qual o ensino evolui, se não os saberes isolados corresponderão à formalização de um ofício que não existe (GAUTHIER, 2013, p. 28).

Desse modo, os saberes dos professores advêm de diversas fontes, que segundo Tardif (2009), são saberes provenientes: da formação escolar anterior, da formação profissional para o Magistério, dos programas e livros didáticos usados no trabalho, de sua própria experiência na profissão, na sala de aula e na escola e os saberes pessoais. Percebemos, assim, que um misto de saberes é colocado em ação pelo professor ao desenvolver o seu ofício. Este o utiliza de acordo com a necessidade, mobilizando os conhecimentos apropriados para cada situação.

Desde tempos longínquos, se vê falar que para ser professora ou professor, se deve tomar o antigo CHÁ, e esse chá deve ser compreendido como: /cê/ de Conhecimento; /h/ de Habilidades e /a/ de Atitudes. E, dessa maneira entendemos que conhecimentos, 
habilidades e atitudes vão se alicerçando no fazer pedagógico, e são próprias do ato de ensinar, e, esses conhecimentos vão cientificando e profissionalizando a ação docente à medida que a formação faz parte da carreira da professora e do professor a reflexão de sua ação docente, e assim refletir a formação e a profissão docente a partir dela, com ela e nela, isto é, no seu principal lócus, que é a sala de aula.

O profissional docente se constitui dentro do seu fazer pedagógico, característica desta profissão tão peculiar, que visa mediar um conhecimento entre vários seres em suas singularidades, e desse jeito vai havendo uma junção dessa mediação, e consequentemente a docente e o docente vão criando um corpus que vai formando seus saberes, saberes esses que fazem parte de um reservatório bem amplo e infinito.

\section{PROFISSÃO DOCENTE: Profissão que exige um profissional complexo}

O ser humano, já sabemos, é um ser complexo, em uma sociedade dinâmica, global, hedonista, consumista, diferencia-se, dessa forma, de outras espécies de seres vivos, logo, é uma tarefa desafiadora e por que não dizer árdua, atuar como mediadora e mediador de conhecimentos diversos. Assim, há a necessidade de formar profissionais complexos, docentes incumbidos da educação formal desse ser humano, o que confirma Imbernón (2011, p. 9) ao dizer que, “[...] a educação dos seres humanos pouco a pouco se tornou mais complexa, o mesmo deverá acontecer à profissão docente."

O cenário atual, do momento pandêmico que estamos vivendo provocado pela COVID-19, no qual nos distanciamos do principal lócus de fomentação do saber discente e docente, que é a sala de aula, e nos adentramos em salas virtuais, salas estas que, exigiram um leque de saberes profissionais atrelados às tecnologias da informação e comunicação fez surgir um novo modelo de profissional docente, que exige saberes até então, não vivenciados por grande parte das professoras e dos professores, bem como das alunas e dos alunos.

De acordo com essa posição Imbernón (2011,) faz a seguinte reflexão,

As enormes mudanças dos meios de comunicação e tecnologia foram acompanhadas por profundas transformações na vida institucional de muitas organizações e abalaram a transmissão do conhecimento e, portanto, também suas instituições. (IMBERNÓN, 2011, p. 9) 
Assim, compreendemos que, a educação complexa entende-se formar profissionais com essa complexidade, ou seja, em constante adaptação aos entremeios da sociedade, onde escolas e professores devem buscar essas mudanças em que a educação atual é formada com todos e para todos, pois visando esse panorama que se intermedeia numa rede cada vez mais plural, onde envolvem todos aqueles que formam, trabalham na educação, isto é, devem buscar este entendimento mutável e complexo não somente as professoras e professores, mas também, gestores (as), supervisores (as), isto é, todos aqueles que fazem e constituem a educação.

Sendo assim, se faz urgente uma reconstrução dos centros de educação formal Imbernón (2011), pois, os lócus onde esses profissionais executam sua profissão precisam também adaptar-se a esse novo modelo profissional, exigindo uma alteração maior do que percebemos, já que atinge transformações políticas, sociais e econômicas.

Nesse contexto, o profissional da educação é aquele em que suas competências e habilidades são aguçadas, fomentadas ao crescimento, à evolução, para assim abarcar seu público, que são educandos e educandas necessitados de uma formação em sua amplitude, para que possam ser autônomos, solidários, competentes; que devem além de apreender os conhecimentos científicos devem saber também, aprender a ser; aprender a fazer; aprender a viver juntos e aprender a aprender, o que se faz urgente e necessário numa sociedade cada vez mais conturbada e caótica.

Imbernón, (2011, p. 64) ilustra dizendo:

Os futuros professores e professoras também devem estar preparados para entender as transformações que vão surgindo nos diferentes campos e para serem receptivos e abertos a concepções pluralistas, capazes de adequar suas atuações às necessidades dos alunos e alunas em cada época e contexto. (IMBERNÓN, 2011, p. 64)

Constata-se assim, que a complexidade do trabalho docente exige a mediação de conhecimentos, planejamento e execução do trabalho, apontando os objetivos, competências e habilidades, o caminho que vai percorrer para alcançar o que se é pretendido. Tudo isso, para atender ao mesmo tempo um público de trinta à quarenta pessoas num só espaço, tendo como pano de fundo, as limitações das pessoas e de ambientes.

PERSPECTIVAS E CAMINHOS PARA A FORMAÇÃO DA (DO) DOCENTE 
A contribuição da formação é fundamental para a construção da identidade profissional e de saberes que envolvam as três dimensões, que é do ser, do saber, e do fazer. Em relação à formação inicial de professores concordamos que:

Dada a natureza do trabalho docente, que é ensinar como contribuição ao processo de humanização dos alunos historicamente situados, espera-se da licenciatura que desenvolva, nos alunos conhecimentos e habilidades, atitudes e valores que lhes possibilitem permanentemente, irem construindo seus saberes fazeres docentes, a partir das necessidades e desafios que o ensino, como prática social lhes coloca no cotidiano." (PIMENTA, 1997, p.06)

Portanto, para responder às demandas e desafios da atualidade, torna-se imprescindível uma formação mais contextualizada e que as instituições de ensino superior possam assumir a formação das futuras professoras e professores, privilegiando como espaço de formação o lócus de trabalho desse profissional, por meio do saber prático do profissional de profissão, que está num processo contínuo de construção e reconstrução de seus saberes docentes.

Nesta perspectiva de fazer com que o futuro professor se aproxime cada vez mais e conheça com firmeza o espaço de atuação e as capacidades que lhe serão exigidas, além disso, ter a possibilidade de fazer uma relação entre a teoria ensinada na academia e a prática tanto almejada, fazendo a imersão no contexto de aprendizagem prático-concreto, de onde emergem as situações reais do cotidiano, trazendo ganhos significativos à formação da futura professora e professor.

No Brasil, especificamente no Maranhão, sabemos que os $\operatorname{programas}^{2}$ de formação de professores em nível de graduação foram excelentes instrumentos utilizados pelas universidades e governos em parceria, para atender aos requisitos da Lei de Diretrizes e Bases $n^{\circ}$ 9.394/96 que exigiu a licenciatura de todos os professores para atuarem na Educação Básica. Eram docentes que estavam em sala de aula, já tinham os saberes da prática, e podiam fazer uma relação significativa da teoria que estavam "recebendo".

\footnotetext{
${ }^{2}$ Alguns programas de formação docente: Programa de Qualificação Docente (PQD), da Universidade Estadual do Maranhão - UEMA; Programa Especial de Formação de Professores para Educação Básica (PROEB), da Universidade Federal do Maranhão - UFMA.
} 
Nesse sentido, esses programas ajudaram os professores a refletirem e discutirem a partir de exemplos da sua realidade, e a desenvolverem uma prática mais embasada articulando teoria e prática. Dessa maneira, entendemos que a prática dos professores é um espaço.

[...] específico de produção, de transformação e mobilização de saberes e, portanto, de teorias, de conhecimentos e de saber-fazer específicos ao ofício de professor. A perspectiva equivale a fazer do professor - tal como o professor universitário ou o pesquisador da educação - um sujeito de conhecimentos, um ator que desenvolve e possui sempre teorias, conhecimentos e saberes de sua própria ação. (TARDIF, 2009, p. 234)

$\mathrm{Na}$ atualidade, as universidades desenvolvem atividades fundamentais na formação inicial que pretendem fazer a inserção desse graduando no espaço da escola, para além do estágio supervisionado, por exemplo, PIBID $^{3}$ e residência pedagógica que dialogam com a ideia que aqui estamos defendendo para a formação pedagógica inicial, e vão ao encontro de muitas sugestões dos professores e professoras que participaram desta pesquisa.

Deverá, então, a futura professora e professor no exercício constante de sua formação, ter oportunidade de refletir mais profundamente sobre as questões desafiadoras da sociedade e da educação contemporânea. Como lidar com situações e temas que surgem no novo cenário em constantes transformações? Conhecimentos esses, essenciais ao repertório cultural desse profissional que desenvolverá uma atividade tão complexa.

Tardif (2009 p. 266) diz que, o objeto de trabalho do professor "são seres humanos e, por conseguinte, os saberes dos professores carregam a marca dos seres humanos". Isto quer dizer que, o professor tem uma "disposição para conhecer e para compreender os alunos em suas particularidades individuais e situacionais." Exigindo, por parte da professora e professor a necessária contextualização dos conhecimentos e saberes, bem como a transposição didática de modo significativo.

Desta forma, ressalta-se a importância desta compreensão do professor para com o aluno como fator preponderante, é um saber não muito difundido, mas algo essencial ao progresso do aluno. A empatia e o acreditar na capacidade do seu aluno como meio de fazer com que o mesmo possa confiar em si mesmo e nas suas capacidades. Sendo o

\footnotetext{
${ }^{3}$ Programa Institucional de Bolsas de Iniciação à Docência.
} 
professor o "detentor do saber e do poder", pois na sala de aula, ainda está com ele a palavra final acerca do resultado do aluno.

No bojo dessa ação pedagógica fazer uma integração salutar entre teoria e prática, buscando o constante exercício da reflexão de sua ação, que, muitas vezes, ocorre de modo conflitante, inquietante, já que objetiva atender sempre uma sociedade plural e mutável, ao mesmo tempo, que deve ter a sensibilidade para a individualidade de cada ser humano que se apresenta em seu caminho para um processo educativo. Cada pessoa é única. Então, embora o professor queira pensar que trabalha para um coletivo não pode desviar o foco para cada um em suas potencialidades e peculiaridades.

Segundo Tardif (2009), “o professor é um ator no sentido forte do termo, um sujeito que assume a sua prática a partir dos significados que ele mesmo lhe dá [...]". Para o autor, os saberes profissionais do professor são personalizados e situados, isto é, constroem-se a partir da historicidade de cada docente e respondem a uma situação particular, onde ganham sentido, constituindo-se em saberes que caracterizam a epistemologia da prática profissional.

\section{EVIDENCIANDO AS VOZES DAS PROFESSORAS E DOS PROFESSORES DO IEMA UP RIO ANIL SÃO LUÍS}

Este estudo de caráter exploratório vem evidenciar as falas dos docentes no que diz respeito à Identidade, Formação e Saberes da Profissão Docente, no qual buscou-se investigar como a formação de profissionais tão relevantes como os da profissão docente exigem amplas reflexões agindo em seu processo de preparação, assim, segue-se com fomentações de discussões dentro dos aspectos identidade-formação-saberes.

No decorrer do estudo, é importante ressaltar que as experiências das autoras na atuação profissional no Magistério estão latentes e dialogando com as teóricas e os teóricos, ressaltando a relevância da formação na construção da identidade das profissionais. Os resultados dos questionários corroboram algumas questões de forma mais pontual sobre o tema.

Desse modo, a técnica de coleta de dados utilizada foi um questionário do Google Forms realizado com o corpo docente, supervisão e gestão do Instituto Estadual de Educação, Ciência e Tecnologia do Maranhão (IEMA), mais precisamente da Unidade Plena, doravante chamada UP, isto é, do IEMA UP Rio Anil, uma escola de ensino 
integral nas primeiras e segundas séries do Ensino Médio, e ainda neste ano de 2021, com $9^{\circ}$ ano do Fundamental e a terceira série do Ensino Médio regular, lócus este que possuem docentes tanto da Base Nacional Comum Curricular (BNCC) quanto da Base Técnica (BT).

Por sua vez, participaram da pesquisa 31 (trinta e um) profissionais da educação da referida escola já citada acima. Diante dessa totalidade, 31 (trinta e uma) respostas obtiveram 14 (catorze) professores $(48,4 \%)$ e 12 (doze) professoras $(38,7 \%)$, ademais de gestão, supervisão, ou que além de professor, o mesmo soma com outras funções. Como aponta o gráfico a seguir.

Gráfico 1 - Apresentando os cargos dos participantes do questionário.

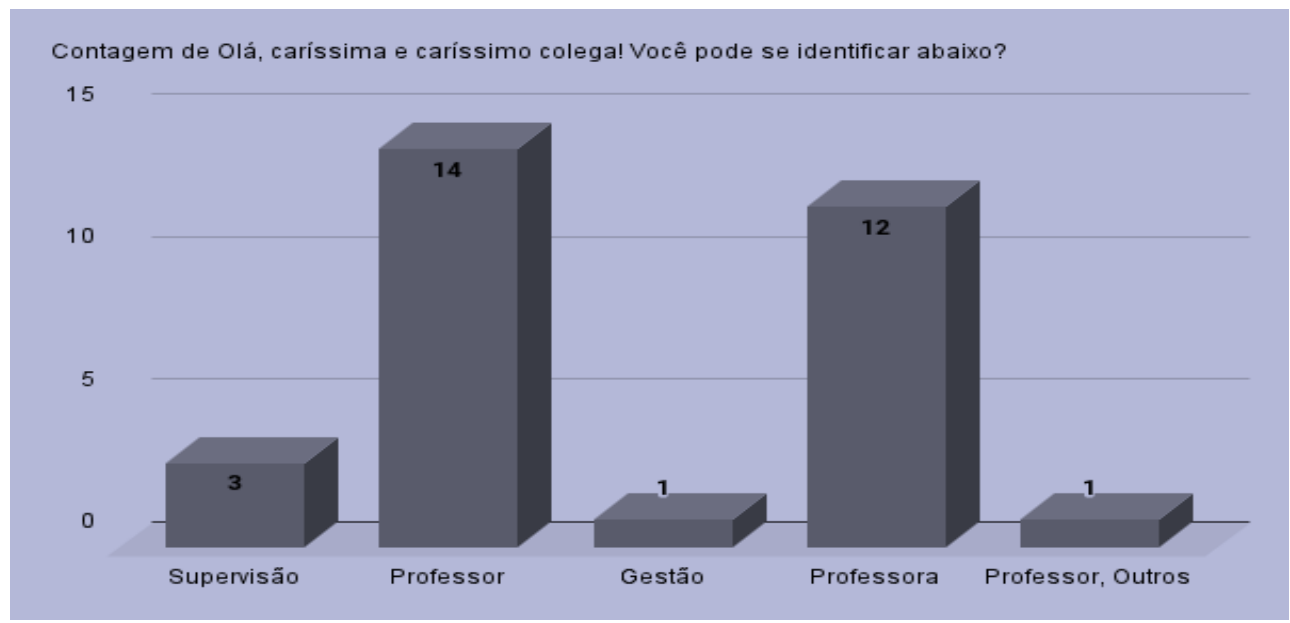

Fonte: (DADOS DA PESQUISA, 2021)

Quanto à formação, a maioria possui especialização, ou seja, 19 (dezenove) docentes que são $65,5 \%$ do corpo docente, e o restante dos profissionais vão se distribuindo entre graduação, mestrado, doutorado. O que podemos identificar no gráfico seguinte.

Gráfico 2 - A formação dos envolvidos na pesquisa. 


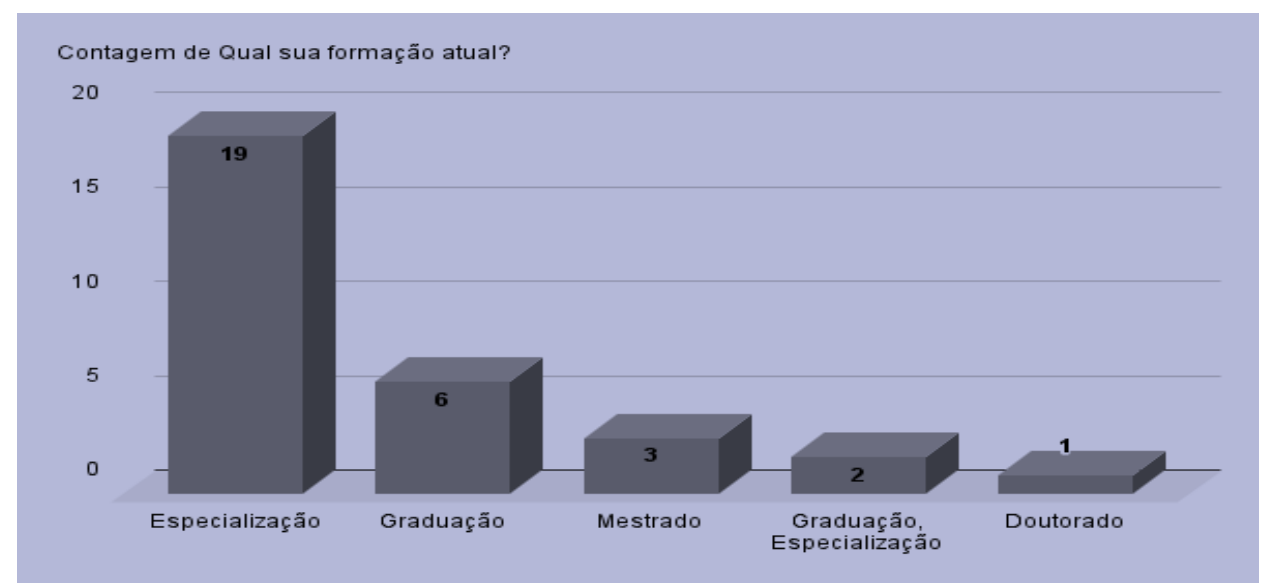

Fonte: (DADOS DA PESQUISA, 2021)

Já, no que se refere ao trabalho na rede pública ou privada, cem por cento (100\%) dos docentes é da rede pública, contudo, houve falha da não opção no questionário de pública e privada, já que é a realidade da grande maioria de nossas escolas do Brasil, há professores e professoras que trabalham tanto na rede pública quanto privada.

No tocante ao tempo de serviço, no ofício da educação, grande parte tem de 11 a 20 anos de exercício do Magistério, isto é, 45,2\%. Como aponta o gráfico que segue.

Gráfico 3 - Tempo de serviço dos envolvidos no estudo.

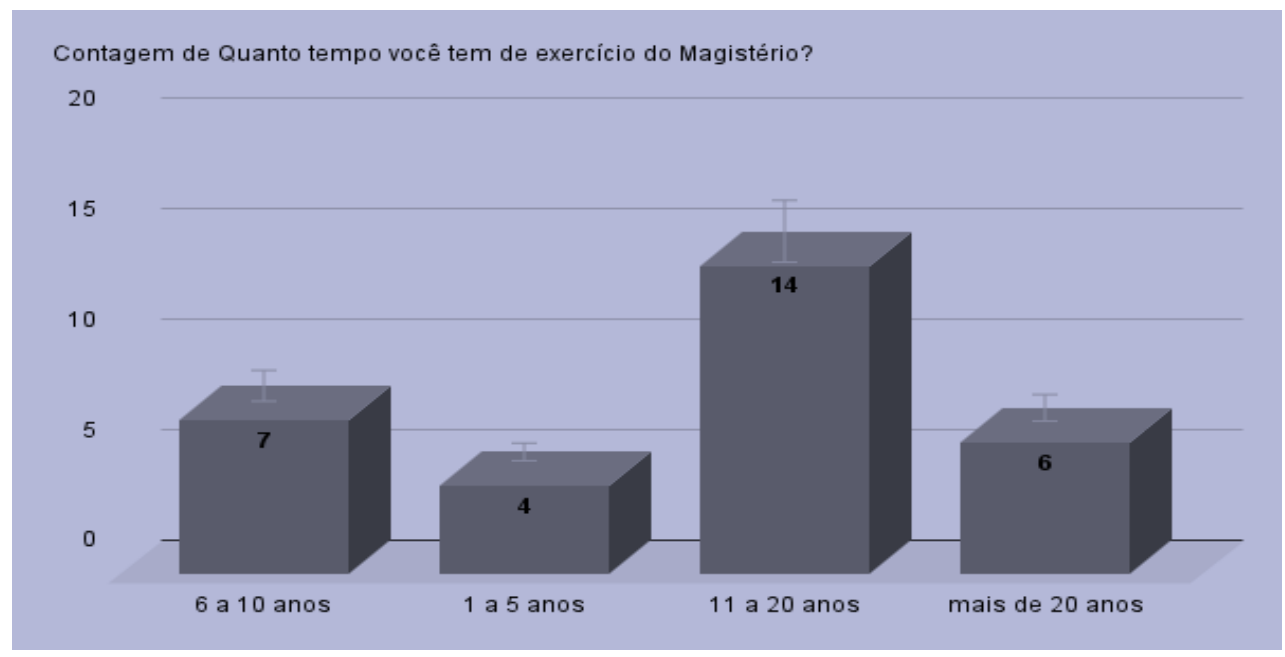

Fonte: (DADOS DA PESQUISA, 2021)

Quanto à identificação com a carreira docente, 96,6\% disseram que se identificam. E, $100 \%$ consideram que sua subjetividade está presente em seu trabalho docente.

Percebemos que, dentro de um número significativo de participações, obtivemos falas importantes, pertinentes, vivas. Desse modo, diante das respostas discursivas, nos propusemos efetuar um entendimento, uma reflexão e discussão a seguir. Em relação ao 
primeiro questionamento por que deve haver preocupação em formar professoras e professores? Na sua maioria, as respostas enfatizaram a questão da melhoria na preparação do professor e aperfeiçoamento da prática:

"Para o aperfeiçoamento da prática pedagógica e apresentação e novos modelos que inovem o processo de ensino." $4(P 1)^{5}$

"Porque a função de mediar o contato dos alunos com o conhecimento é muito desafiadora." (P4)

"Para o processo ensinoaprendizagem possa ser efetivo." (P5)

"Para que os mesmos estejam sempre revendo suas práticas docentes e aperfeiçoando a mesma." (P8)

"Melhoria na qualidade do ensino/aprendizagem." (P10)

"Para que tenham segurança no que fazem e, assim transmitir com segurança." (P11)

Depreende-se das respostas dadas que a concepção de formação está ligada à capacitação profissional, à aquisição de saberes e informações, que darão ao docente poder para o exercício do ensino com qualidade. Contudo, ao relacionarem seus conhecimentos e significados dados à formação na perspectiva de "informação" é importante ressalvar e entender que,

Inteligência tem a ver com a arte de vincular conhecimento de maneira útil e pertinente, isto é, de produzir novas formas de progresso e desenvolvimento; consciência e sabedoria envolvem reflexão, isto é capacidade de produzir novas formas de existência, de humanização. E é nessa trama que se pode entender as relações entre conhecimento e poder. (PIMENTA, 1997, p. 8).

Algumas dessas respostas relacionam a formação à troca de experiências com seus pares:

"Porque para o exercício dessa tão nobre profissão é necessário que haja troca de riquíssimas experiências jávivenciadas por outros profissionais da área educacional." (P2)

"Para que os saberes sejam construidos e compartilhados." (P11)

\footnotetext{
${ }^{4}$ As falas foram transcritas conforme o original.

${ }^{5}$ A letra pê /P/ usada nas falas significa professor/professora e o número a ordem dos questionários.
} 
Nessas falas, configura-se uma concepção da prática pedagógica como espaço de análise, reflexão e construção de saberes. Isso significa que,

Nas práticas docentes estão contidos elementos, tais como a problematização, a intencionalidade para encontrar soluções, a experimentação metodológica, o enfrentamento de situações de ensino complexas, as tentativas mais radicais, mais ricas e mais sugestivas de uma didática inovadora, que ainda não está configurada teoricamente (PIMENTA, 1997, p. 11).

Ainda houveram respostas ligadas à valorização do trabalho, com a preocupação da formação de futuros profissionais para atuar na sociedade:

"Tem que haver essa preocupação pois necessitamos de professores para ajudar na formação de ideias e princípios para o educando." (P3)

"Porque a formação de profissionais de educação está em escassez por vários motivos, como por exemplo a própria valorização e respeito pelos educadores." (P7)

No tocante à questão: Que relação podemos fazer entre formação-profissãoensino? Foram selecionadas respostas que apresentam a relação existente nessa tríade.

"É uma relação de valores que tem como objetivo dar uma relevância maior de práticas para ajudar os educandos." (P3)

"Existe a necessidade dessa relação ser estabelecida de maneira latente evidenciando sempre essa parceria." (P5)

"A formação é indispensável para nossa formação profissional, por meio dela podemos desenvolver habilidades para melhorar nossas práticas e consequentemente o ensino." (P8)

"O profissional bem formado... terá maior desempenho na sua profissão.” (P10)

"A formação identifica as competências para o exercício da profissão e tem-se no ensino o exercício da profissão docente." (P21)

Por meio das falas, percebe-se o entendimento da correlação estabelecida entre a busca pela formação como aperfeiçoamento profissional e seu impacto no ensino. Sua relevância para o desenvolvimento da profissão em um diálogo permanente que produzirá avanços na educação como um todo. Dessa forma, é inseparável pensar que se possa ensinar sem a constante formação, e que haja formação sem haver reflexos no ensino e na profissão docente. 
Quando perguntados sobre a contribuição da formação para sua atuação, observamos que 21 (vinte e uma) pessoas, o que corresponde a 67,7\% disseram que tem tido uma grande contribuição, apenas 1 (uma) disse que não, outra declarou que não está participando atualmente, e 16,1\% apontaram que tem contribuído parcialmente. Duas falas pontuam a ausência de políticas de formação continuada:

"Nas minhas práticas sim, mas no geral a maioria infelizmente não tem recursos financeiros e tempo para melhor formação." (P6)

"Quais? As que eu faço por conta? O estado, a faculdade, a família, a sociedade não estão nem aí pra educação na prática." (P19)

Em algumas das respostas, ficou explícito que essa contribuição tem a ver com a questão prática da formação docente, como por exemplo, nesta:

"Sim. Destaco, durante a minha graduação, o PIBID e a Residência Pedagógica. Essas experiências estão transformando a formação da licenciatura." (P10)

As respostas positivas destacam a ligação da formação com a melhoria das práticas. Numa análise geral, a preocupação da quase totalidade dos professores com questões formativas foi notória, ficando explícita na resposta:

“A formação capacita o professor para o ensino." (P4)

A estudiosa Ilma Passos (2012) afirma que, pensar na formação docente é reconhecer essa formação e a importância dela. Compreender este profissional da educação como um trabalhador de uma sociedade enraizada de suas nuances. Logo, a formação é importante para o exercício da docência. A profissionalização está atrelada às capacidades específicas desta profissão porque a docência é uma atividade profissional.

Sobre o questionamento: Como fazer para que a formação inicial se aproxime da realidade escolar e do exercício profissional da professora e do professor? As respostas, na maioria, deram destaque para a necessidade de o futuro professor conhecer a realidade na qual irá exercer sua profissão.

"Aliando a teoria à prática, oportunizando ao professor em formação contato com a aplicação do real do que é ensinado." (P1) 


\begin{abstract}
"Reconhecendo essa realidade como fator determinante desse equilíbrio." (P5)

"Acredito que simular situações escolares ou mesmo vivenciar nas salas de aula com estágios." (P6)

"Por meio de avaliações e compartilhamento de experiências." (P7)

"Direcionar a metodologia e didática às práticas de ensino, extensão e pesquisa desde o ensino médio de fato." (P8)

"Acredito que desde a formação inicial deve-se buscar desenvolver um trabalho compativel com a realidade escolar." (P12)

"Imersão mais cedo a cada novos aprendizados, porém com momentos de análise e reflexão, retornando para a prática." (P24)
\end{abstract}

Para o autor Francisco Imbernón (2011), a formação inicial deve estar interligada à formação permanente, e ambas devem atuar de maneira a construir sempre uma práxis, e desse modo atrelar a teoria e prática. E, que o profissional docente se constrói em sua ação pedagógica. Já para Silmara Papi (2005), o profissional docente deve ter entendimento que ele se forma em seu ofício, em seu fazer pedagógico. E esta ação está atrelada ao local em que desempenha esses saberes teóricos e práticos.

Assim como, qualquer profissão vai atribuindo-lhe singularidades profissionais conforme o ambiente em que desenvolve tais conhecimentos, assim o é com a profissão docente. A formação faz um entrelace entre a complexidade da educação, a profissão e a profissionalidade. E a importância desta profissionalização docente, se constrói através das características peculiares desta profissão.

Sobre a importância da formação docente, podemos salientar Marli André (2016), quando percebemos que para a autora, a formação docente deve ser refletida desde a formação inicial ademais de ser contínua, fazendo uma junção entre teoria-práticapráxis, tendo como intuito formar profissionais que construam e evidenciam sua identidade docente. E, dentro desta identidade está como papel primordial formar docentes, pesquisadoras e pesquisadores.

A profissionalização se dá num processo de autonomia, colaboração e cooperação. E, Betânia Leite Ramalho (2004), nos faz refletir que a formação é importante para trazer ante a esses profissionais entendimentos de sua profissão, isto é, conhecimentos fundamentais ao exercício de sua profissão. É na formação que compreendemos o que é exigido para o desempenho de tal trabalho. São ações que visam encarar sua profissão com profissionalidade. É saber que o professor contribui para a formação de uma 
identidade profissional. E nesse desafio entre a teoria e a prática vai formando sua profissionalização.

No tópico: Na sua opinião, quais são os saberes necessários aos profissionais da docência? As respostas foram bem variadas:

“Didática, tecnologias voltadas para educação." (P1)

"Professor sempre tem que saber o interesse de aula." (P2)

"Todas as práticas que serão utilizadas no processo ensino aprendizagem." (P3)

"Os professores precisam ser capazes de perceber cada aluno como indivíduo, e assim, estar a par das diversas estratégias de ensinoaprendizagem e avaliação." (P4)

"Considerar a vivência dos nossos alunos, os conhecimentos prévios, sua historicidade.” (P5)

"Conheceros conteúdos e a dinâmica do processo ensino $e$ aprendizagem, saber colocar em prática esse conhecimento e vivenciar contextualizando, quando possivel." (P6)

"Capacidade crítica de análise de cenários. Contextualização com a teoria e prática. Promover uma cultura de paz às diversidades/pluralidade." (P7)

"Saberes que possam ser levados para os discentes de acordo com sua realidade e associados pelos mesmos, em atividades que os conteúdos sejam na prática relacionados à vida dos alunos na sociedade.” (P8)

"Sabe-se que os saberes necessários aos profissionais da docência são, além da disciplina, as experiências e a ação pedagógica." (P12)

"Vivência/experiência, sensibilidade e conhecimento de causa." (P13)

“Conhecer, fazer e ser." (P14)

“Competência ante aos conteúdos e habilidades em ação." (P 15)

"Saberes específicos da área; conhecimentos pedagógicos e sociológicos." (P18)

"O primeiro é o conhecimento de didática e transposição didática. Depois os próprios conhecimentos da disciplina, assim como saberes da rua e de vida. Além disso inteligência emocional e escuta empático." (P22)

"Profissionalização, docência, conhecimento e empatia." (P23) 
As respostas revelam a complexidade do exercício da profissão docente que exige uma formação específica e ao mesmo tempo ampla, destacam desde aspectos do saberfazer do professor (didática), bem como a preocupação com a formação humana e a condição histórica do discente. Desde atributos pessoais exigidos nas relações sociais até a dimensão da necessidade de atualização dos conhecimentos no contexto da realidade social.

Sendo assim, é importante que a formação docente, além do aspecto voltado às questões da prática, como um saber-fazer, também fomente posturas que visem à construção de uma educação libertadora, emancipadora, humanizadora, tornando-se espaço reflexivo sobre as contradições e os conflitos existentes na sociedade. Ou seja, refletir sobre o papel do professor e da escola frente aos problemas da realidade numa sociedade cada vez mais globalizada e individualista.

Quando arguidos sobre a competência docente residir no fato de serem suficientes "conhecer o conteúdo, ter talento, ter bom senso, seguir sua intuição, ter experiência, cultura" (Gauthier), os docentes ressaltaram que esses são elementos importantes, mas também, outros aspectos ligados às relações interpessoais e com a realidade da escola foram destacados:

"É preciso conhecer o projeto político no qual a escola está inseria assim como devemos ter também empatia com nossos alunos." (P16)

"Não. Como já foi dito, é necessário que o professor tenha sensibilidade também com o meio em que o aluno está inserido, para que consiga trazer todos os alunos para ele, ou pelo menos quantos for possivel." (P19)

"Tudo citado por Gauthier são importantes, mas sempre devemos ponderar outros fatores que aparecem no chão da escolar, no contato direto com os alunos." (P20)

"O professor agrega muito o que é nas suas aulas, então o ser $e$ conviver, como ser empático, faz parte das relações humanas $e$ profissionais." (P5)

As falas demonstram a percepção dos pontos aqui avaliados a saber: identidadeformação-saberes da docência. Elas revelam como é complexa a articulação dessa relação e como o (a) docente busca no seu dia a dia meios para que sua formação dê conta do recado, da tarefa de bem ensinar. São falas de quem lhes são de direito, de quem vivencia a realidade das escolas públicas de nosso país, de quem tem propriedade dessas nuances 
tão singulares às professoras e professores. Profissionais esses tão importantes para o desenvolvimento do nosso país, bem como a valorização do Magistério.

\section{ALGUMAS CONSIDERAÇÕES}

Valendo-se das leituras dos diversos autores aqui apresentados, notamos que, a profissão docente ainda requer um melhor entendimento acerca de algumas de suas nuances. Como por exemplo, formação, identidade e saberes. Averiguando, aprimorando tais entendimentos, podemos agora empreender uma resposta à pergunta apresentada no momento introdutório de nosso estudo. Pergunta esta que iremos mencionar novamente: Como a formação contribui para a prática de profissionais tão complexos como os da profissão docente?

Com base na pesquisa empreendida, podemos dizer que, vem contribuindo de forma significativa um tipo de formação que compreende a complexidade da profissão docente, que dialoga com os problemas e desafios da prática pedagógica de forma efetiva e que traz em menor ou maior medida uma preparação para atuação futura ou transformação à prática do professor em exercício. O eixo de reflexão são as problemáticas docentes imersas no fazer pedagógico.

Portanto, o pano de fundo da formação é a realidade da escola, é a reflexão das problemáticas docentes. Partindo desse pressuposto a formação também deve propiciar a busca da autoformação e do autoconhecimento, na perspectiva dos desafios da atualidade. Que tenham como formadoras e formadores profissionais cônscios dessa realidade e capazes de corresponder a essas necessidades e desafios.

Sendo assim, nada mais coerente que essa formação seja assumida por professoras e professores. Isto é, professoras e professores que tomem a formação como um espaço de pesquisa. Para tanto, que sejam docentes em constante trabalho no chão da escola, conhecedores da realidade, e ao mesmo tempo, que empreendam a busca da própria formação, tão singular e tão necessária para assim somar com seus pares.

Nesta configuração do professor-pesquisador, o espaço de formação torna-se preponderante para se pensar e refletir sobre os problemas que estão dentro da escola, num movimento de ação-reflexão-ação, buscando soluções em conjunto, em colaboração com seus pares, direcionando a ação e o esforço dos atores escolares para pensar na escola com seus problemas e dilemas, na perspectiva da escola reflexiva (IMBERNON, 2011). 
Portanto, as nuanças da profissão docente: formação-identidade e saberes demonstram a complexidade do trabalho da docência, enquanto profissionais complexos que exigem formação complexa, com espaços e tempos que ajudem a desenvolver uma consciência de que sua formação deve ser contínua, permanente, reflexiva e colaborativa, tendo como centralidade a investigação das problemáticas que afligem a escola.

Diante dessa complexidade da formação dessas e desses profissionais da docência, Imbernón (2011), também nos ajuda a entender a complexidade da educação e, logo, o processo formativo deveria visar formar esses profissionais com tal complexidade, preparados para uma sociedade dinâmica e também complexa. O professor deve buscar sempre acompanhar as mudanças resultantes da sociedade em movimento, e assim contribuir com discentes autônomos, solidários, competentes, e que atuem criticamente em um mundo globalizado.

Não obstante, a formação profissional da professora e do professor deve propiciar uma profunda conscientização de seu papel de ator na trama social, uma reflexão profunda acerca das intencionalidades das suas ações, levando ao questionamento permanente sobre o que faz, como faz e para quem faz, a fim de trazer o desvelamento de uma prática, e sua posição como agente de reprodução ou de transformação. Nesse sentido:

\begin{abstract}
A adoção consciente de uma teoria é, pois, uma necessidade da prática docente. De fato, não há práticas em teoria. Toda prática docente fundamenta-se numa concepção de educação, de criança, de infância; toda prática docente deriva uma maneira de conceber o lugar do professor, o lugar da criança que aprende. O lugar da cultura, a partir da teoriaem que se apoia e que pode estar clara ou não para o professor (TEIXEIRA; MELO).
\end{abstract}

Dessa forma, afirmamos a importância de uma formação docente como instrumento de transformação das realidades escolares. A formação docente crítica e reflexiva a partir das questões latente em que vivem os docentes nas suas realidades, do seu protagonismo e do trabalho colaborativo consolidará uma prática de formação que contribuirá para a transformação das realidades da escola, e finalmente com a construção de uma sociedade mais equânime e solidária. 


\section{REFERÊNCIAS}

ANDRÉ, M. Práticas inovadoras na formação de professores. Campinas-SP: Papirus, 2016, cap.01, p. 17-34. (Coleção Prática Pedagógica)

GAUTHIER, C. Por uma teoria da Pedagogia: Pesquisas contemporâneas sobre o saber docente. Ijuí-RS: Editora INIJUI, 2003. p. 1-74.

IMBERNÓN, F. Formação docente e profissional: formar-se para a mudança e incerteza. Tradução Silvana Cobucci Leite. 9. ed. v. 14. São Paulo: Cortez, 2011. (Coleção questões da nossa época)

PAPI, S. de O. G. Professores: formação e profissionalização. Araraquara, SP: Junqueira\& Marin, 2005.

PIMENTA S. G. Formação de professores:saberes e da docência e identidade do professor. Nuances, São Paulo, v. 03, n.03, p. 05-14, set.1997. Disponivelem: https://revista.fct.unesp.br/index.php/Nuances/article/view/50. Acessoem: 30 nov. 2021

RAMALHO, B. L.; NUÑEZ, I. B.; GAUTHIER, C.Formar professor, profissionalizar o Ensino - perspectivas e desafios. Porto Alegre: ${ }^{a}$ Ed. Sulina, 2004.

TARDIF, M. Saberes docentes e formação profissional. 16.ed. Petropólis-RJ: Editora vozes, 2014.

TEIXEIRA, S. R. dos S.; MELLO, S. A. Formação de Professores: uma teoria para orientar as práticas. In: CORRÊA, C. H. A.; PESSOA, L. I.; BISSOLI, M. de F. (Orgs). Formação de professores em perspectiva. Manaus: Edua, 2016, p. 85-108.

VEIGA, I. P. A.; D’ÁVILA, C. (Orgs). Profissão professor: novos sentidos, novas perspectivas. 2 ed. Campinas-SP: Papirus, 2012. (Coleção Magistério: Formação e Trabalho Pedagógico). 